\title{
Lina Beck-Bernard y Domingo Faustino Sarmiento en el punto de tangencia
}

\author{
María Luisa Ferraris ${ }^{\bullet}$ \\ CEC - Universidad Nacional del Litoral
}

\begin{abstract}
Resumen
Este artículo intenta presentar las coincidencias ideológicas y literarias de dos protagonistas de la historia argentina en la segunda mitad del siglo XIX: Domingo Faustino Sarmiento y Lina Beck-Bernard, durante los comienzos del fenómeno de la inmigración masiva en nuestro territorio. A través de un estudio comparado se realiza la aproximación a las ideas y discursos narrativos en dos obras literarias de ambos autores, Facundo y El río Paraná. Cinco Años en la Confederación Argentina, enfocando particularmente las ideas de civilización y barbarie, el tema del indio y el tratamiento literario de las descripciones del entorno social y del paisaje. A pesar de pertenecer a mundos culturales diferentes y de haber tenido un origen muy distinto uno del otro, de las lecturas de las obras de Sarmiento y Lina Beck-Bernard se puede establecer un patrón común de teorías sociológicas que responde, no sólo al ideario subjetivo, sino también a los cánones en boga a mediados y en la segunda mitad del siglo XIX. Por último, y considerando que sus historias personales coinciden en tiempo y espacio en la ciudad de Santa Fe, en los días de la Convención que realiza la primera reforma a la Constitución de 1853 , se especula acerca del posible y probable encuentro de ambos en esa circunstancia histórica (1860), utilizando ciertos indicios documentales y bibliográficos.
\end{abstract}

\section{Palabras clave}

· Sarmiento · Lina Beck-Bernard · civilización · barbarie · literatura

\footnotetext{
- Profesora en Letras y Docente de Lengua Italiana. Ex catedrática en la Universidad Católica de Santa Fe y la Universidad Nacional del Litoral. Especialista en enseñanza de la Lengua Italiana y Didáctica y Práctica de las Lenguas Extranjeras. Becaria del Gobierno Italiano en Perugia y Siena (Italia). Corresponsal Consular Honorario de Italia, Presidente de la Asociación Dante Alighieri y Responsable del Centro Certificador de PLIDA en Monte Caseros, Corrientes. Actualmente integra las Comisiones del Centro Piemontés de Santa Fe, de la Asociación de Mujeres Piemontesas de la R.A. (AMPRA) y de la Asociación Santafesina de Escritores (ASDE). Forma parte del equipo del Portal de la Memoria Gringa y del Centro de Estudios Comparados de la UNL. Distinguida por la Comisión Pari Opportunitá del COM.IT.ES (2007). Diploma del Circolo dei Cavalieri de Argentina al Ciudadano Italoargentino distinguido (2016), Premio Piemontés Nacional por FAPA (2017). Autora de los libros de cuentos El malón y otros relatos. II malón ed altri brevi racconti, en edición bilingüe (Dunken, 2015) y Árbol de lluvia (Dunken, 2017).
} 


\section{Abstract}

This article configures an approximation to a comparative study of Sarmiento and Lina Beck-Bernard's personalities and ideas and seeks to find suggestive coincidences and differences not only in terms of their writings but also in the way they conveyed their actions and their incidence in the society and political spectrum of their time. Regardless of the fact that they both belonged to culturally different worlds and came from very different backgrounds, when reading Sarmiento and Lina Beck-Bernard's masterpieces, the reader can establish a common pattern of sociological theories that attests not only to their subjectivities but also to the literary canons in vogue in the first and second half of the nineteenth century. In other words, the ideas of civilization and barbarism, the question of indigenous people and the literary treatment of descriptions around the notion of social and natural landscapes.

\section{Key words}

Sarmiento · Lina Beck-Bernard · civilization · barbarism · literature

La tangente a una curva en un punto es una recta que toca a la curva sólo en dicho punto llamado "punto de tangencia». Esta noción se puede generalizar, desde la recta tangente a figuras tangentes en dos dimensiones hasta los espacios tangentes, en donde se clasifica el concepto de tangencia en más dimensiones.

(N. del A.)

\section{Sarmiento y Lina Beck-Bernard: universos de ideas paralelas}

El 11 de setiembre de 1888, en Asunción del Paraguay, moría Domingo Faustino Sarmiento. Gran escritor y político argentino que, con todas sus debilidades y flaquezas humanas, iluminó el siglo XIX como pocos en estas latitudes. Su obra fue inmensa, considerando que nació pobre y que, empoderándose de su destino, llevó adelante una labor literaria, política y educativa con una energía arrolladora. Lector y escritor, maestro y periodista, viajero y militar, cuando fue necesario, gobernador de su provincia, legislador, ministro y presidente de la nación, vivió una parte de su vida en el exilio, pero estuvo siempre presente en la vida de la Argentina. Imaginó un país distinto, tocado por la vara del progreso continuo, y su Presidencia fue de las más prolíficas en obras materiales y culturales. Enamoradizo, apasionado y frontal, tampoco escatimó fuerzas y recursos en el amor y en las lides políticas. Su libro más fa- 
moso, Civilización i Barbarie. Vida de Juan Facundo Quiroga. I aspecto fisico, costumbres $i$ ábitos de la República Arjentina, que le concediera renombre en el mundo entero, se publicó en 1845 como suplemento del diario El Progreso, en Santiago de Chile. Su tercera edición fue publicada en castellano por Appleton y Cía. en Nueva York y la cuarta fue publicada por la Librería Hachette y Cía. en París, en 1874. Como expresara el escritor santafesino Luis Di Filippo: «Es una obra original, tan personal, tan de la idiosincrasia de Sarmiento que es como Sarmiento mismo: algo que desborda, que se impone, que agita, que conmueve...» (Di Filippo, 1949: 27).

En el mismo año de 1888, pero el día 27 de setiembre, moría en Lausana (Suiza), Amélie (Lina) Bernard, que llega al Río de la Plata acompañando a su esposo, Charles Beck quien, junto a Aquiles Herzog, había fundado una compañía colonizadora que daría origen a la colonia San Carlos, al suroeste de la ciudad de Santa Fe. Dueña de una lúcida personalidad, observadora y atenta a las cosas y sucesos de su entorno, a las actividades del cuidado de su propia familia agregó las de la vida social y la escritura. Lina Beck-Bernard ha dejado testimonio de su paso por nuestra región a través de distintos libros, de los cuales Le Rio Párana. Cinq années de séjour dans la République Argentine (traducido como El rio Paraná. Cinco Años en la Confederación Argentina por José Luis Busaniche) publicado en París, por la librería Grassart en 1864, es el más conocido. Relatos, novelas y ensayos sobre la condición de la mujer en situaciones vulnerables completan una producción que revela, no sólo sus dotes imaginativas, sino además su pensamiento progresista alimentado por una sólida educación recibida en Europa y movido por la pasión y la piedad que se rebela ante las injusticias de la sociedad. Lina permaneció en estas tierras desde 1857 a 1862 y, junto a su esposo, formaron parte del círculo social más importante de la ciudad de Santa Fe, situación que les permitió establecer relaciones con personalidades de la vida política, comercial y empresarial de la Confederación Argentina. Un dato que permite calificar la importancia de la presencia del matrimonio en nuestra región es que, en agosto de 1860, Charles Beck ocupa la Presidencia del Club del Orden hasta febrero de 1861.

¿Por qué asociar a Sarmiento y a Lina Beck-Bernard? En primer lugar, además de haber vivido sus vidas por entero dentro del siglo XIX, hay entre ellos otras coincidencias y diferencias sugestivas no sólo en sus escritos sino también en el transitar de sus acciones y su incidencia en la sociedad y en la política de su tiempo.

A pesar de pertenecer a mundos culturales diferentes y de haber tenido un origen muy distinto uno del otro, de las lecturas de las obras de Sarmiento y Lina Beck-Bernard se puede establecer un patrón común de teorías sociológicas que responde no sólo al ideario subjetivo, sino también a los cánones en boga a mediados y en la segunda mitad del siglo XIX. Analizaremos aquí brevemente, y a modo de muestra, algunos de estos elementos en sus obras nombradas más arriba: las ideas de civilización y barbarie, el tema del indio y el tratamiento literario de las descripciones del entorno social y del paisaje.

Civilización y barbarie constituían ya en ese tiempo conceptos antinómicos ampliamente conocidos y crecidos desde el siglo XVII. Conformaban imágenes y representaciones del mundo heredadas de la Ilustración y alimentadas desde la Grecia clásica - y su idea del extranjero y del invasor como un otro ajeno y distinto 
del mundo helénico— del Imperio Romano, donde los bárbaros eran aquellos que no poseían la ciudadanía, la civitas.

Civilización y barbarie fueron palabras que entraron, con distintos matices, en el debate socioantropológico europeo del siglo XIX asociadas a la idea del progreso material y cultural. Desde Europa se trasladaron a América a través de los viajeros y los libros que llegaron a los lectores y estudiosos autóctonos. Las ideas de autores, sobre todo franceses, suscitaban tertulias, reuniones y debates. Rousseau, Montaigne, Lerminnier, Tocqueville, Guizot, Leroux, Coussin eran llevados «en los bolsillos» de toda una generación de jóvenes, apasionados por la filosofía y la política, algunos de los cuales lograrían hacer incidir esas ideas en el proyecto de Nación que comenzó a gestarse en 1852. Así lo confirma Sarmiento en Recuerdos de Provincia:

i concluido aquel curso, empecé a sentir que mi pensamiento propio, espejo reflector hasta entonces de las ideas ajenas, empezaba a moverse i a querer marchar. Todas mis ideas se fijaron clara i distintamente, disipándose las sombras i vacilaciones frecuentes en la juventud que comienza, llenos ya los vacíos que las lecturas desordenadas de veinte años habían podido dejar, buscando la aplicación de aquellos resultados adquiridos a la vida actual, traduciendo el espíritu europeo al espíritu americano, con los cambios que el diverso teatro requería. (Sarmiento, 2003: 95)

Civilización y barbarie conformaban esferas conceptuales caracterizadas por una matriz simbólico-cultural que se reproducía en otras ideas antagónicas y asociadas a la vez: ciudad-campo, europeo-indio, cultura-ignorancia, soberanía-esclavitud, progreso-involución. De un modo estereotipado podríamos decir que el mundo civilizado se reconocía en la ciudad, en todo lo que venía de Europa, en la cultura, en la soberanía y el progreso. Por el contrario, la idea de barbarie se asociaba al campo, al indio, a la ignorancia, a la esclavitud y a la involución de un pueblo. En palabras de Noé Jitrik:

Así, Civilización es un término necesario para saber qué es y significa para el país la ciudad; barbarie para saber qué es y significa la campaña. Por idéntico pasaje, unitarios u hombres formados a la europea se enfrentan a los caudillos. (Jitrik, 1968: 15)

Esta visión sumaria del fenómeno no echa luz sobre los claroscuros que sí aparecen en muchos escritos de la época, siempre que no se trate de producciones panfletarias con un determinado tinte político. Así, Facundo. Civilización y barbarie, si bien aparece en publicaciones periodísticas con características de libelo, durante el exilio chileno de su autor, es una obra compleja y contradictoria, que expresa el ataque a Rosas a través de la figura del «Tigre de los Llanos». Sarmiento encierra en los límites de su libro un universo de ideas que entran en conflicto entre sí estableciendo una dialéctica de una cierta raigambre hegeliana, donde laten sus propias batallas interiores y las ambigüedades que percibe detrás de la opacidad de sus principios, en un proceso permanente de autocuestionamiento y de aprendizaje.

La fórmula antinómica civilización y barbarie es utilizada también por Lina Beck-Bernard en su obra El Río Paraná: cinco años en la República Argentina 1857-1962. La autora distingue "la brillante civilización de Buenos Aires», que se manifiesta en el gran estilo de sus construcciones y en el porte majestuoso de 
las mujeres, y la barbarie expresada en la imagen del desierto, de "cierta tintura asiática» (como diría Sarmiento) cuando emprenden el viaje hacia Santa Fe: «... Hay que prepararse para dejar Buenos Aires, sus casas suntuosas, sus palacios y sus lujos. Fuerza es abandonar esta brillante civilización e internarnos en el desierto». (Beck-Bernard, 1991: 34)

$\mathrm{Al}$ igual que Sarmiento, que afirma el condicionamiento que ejerce sobre el carácter de Facundo la campaña pastoril en la que vive, nuestra autora, además de elogiar y distinguir entre instrucción y educación al referirse a las mujeres de estas tierras, expone el condicionamiento que la geografía les impone:

Disponen de mucha inteligencia y lo aprenden todo con facilidad. Es cierto que estas cualidades sobrenadan en un fondo de indolencia, de ignorancia y de superstición, pero se advierten en seguida los buenos elementos fundamentales. Estos espíritus tienen mucho del suelo en que viven: excesivamente rico y fértil en cuanto se le trabaja, pero de ordinario, abandonado y baldío. (Beck-Bernard, 1991: 38-39)

Cuando describe la fiesta del 25 de Mayo en el Cabildo de Santa Fe, encuentra la oportunidad de contraponer Civilización y Barbarie de manera contundente, a través de dos personajes, una dama de la alta sociedad santafesina y una india:

Era el lujo de la civilización junto a la barbarie, tal como Santa Fe a las puertas del Chaco. Ambas mujeres personificaban de manera sorprendente, dos razas que se mantienen enemigas después de trecientos años y que lo serán siempre como los pueblos desposeídos frente a sus invasores. (Beck-Bernard, 1991: 43)

La literatura argentina del siglo XIX está atravesada por la temática del indio ligada a las vastedades del territorio e identificada sociológicamente con la barbarie (Echeverría, Hernández, Mansilla). En estas latitudes, no se trata precisamente de la representación social del «buen salvaje» (Rousseau), sino del otro en cuanto problema y obstáculo en relación con el proyecto civilizador. Por lo tanto, las alternativas se cuentan como resolución del problema y eliminación del obstáculo. Ambas se aplicaron en distintos tiempos y lugares y con diversos protagonistas. A medida que se produce el proceso inmigratorio, la presencia del indio, a caballo de su raza, inspira al europeo admiración y temor. Es el otro en su entera mismidad, como una expresión propia del desierto:

De pronto vemos ante nosotros un indio, de pie, junto a su caballo. Ha clavado la lanza en la arena y ajusta un atado a un lazo envuelto al pescuezo del animal. Es de aventajada estampa y su figura parece fundida en bronce. Nos mira pasar con ojos huraños y aire receloso pero sigue en su tarea sin parecer ocuparse de nosotros. ¿Cómo y por qué se encontraba allí? No sabíamos explicarlo. Hubiérase dicho surgido de la tierra. (Beck-Bernard, 1991: 62)

La actitud hiératica del aborigen es una característica que ambos autores manifiestan en sus escritos. En Conflicto y armonía de las razas en América (obra considerada producto de la vejez y la vanidad por su propio autor), Sarmiento dice de «nuestros padres prehistóricos» (sic): 
La seriedad de la posición en reposo de los músculos de la cara, y la gravedad del porte, son generales a todas las tribus indígenas, como expresión de dignidad personal en los varones y de impasibilidad, que en realidad toca en el estoicismo cuando hacen frente al dolor, al miedo, a la alegría, lo mismo que al martirio. (Sarmiento, 1915: 77)

Y Lina Beck-Bernard: «Pesa sobre su cerebro una especie de inercia fatal y misteriosa que condena su pensamiento a replegarse sobre sí mismo y a no traspasar ciertos límites» (Beck-Bernard, 1991: 48).

Sarmiento analiza este tema desde la mirada globalizadora que abarca el entero plan de civilización y progreso que prevé para la Nación argentina, basado en la constitución de una república instrumentada mediante la educación primaria y la división de los latifundios en colonias agrícolas. Por ello discrimina al indio como elemento negativo, porque desde la determinación de su óptica de estadista, el aborigen no sólo es un obstáculo en el proceso civilizador sino que jamás podrá alcanzarlo. Dice en Recuerdos de Provincia: «Todo está allí, menos el jenio del hombre, menos la intelijencia i la libertad. Los blancos se vuelven huarpes, i es ya grande título para la consideración pública saber tirar las bolas, llevar chiripá, o rastrear una mula!» (Sarmiento, 2003:10). Y en Facundo: «Las razas americanas viven en la ociosidad y se muestran incapaces, aun por medio de la compulsión, para dedicarse a un trabajo duro y seguido» (Sarmiento, 1971: 29).

Hay, en cambio, en la mirada de Lina Beck-Bernard, el poético sentimiento de piedad en la expresión de su espíritu romántico europeo cuando se refiere a la «vaga tristeza» y la «melancolía soberbia» del indígena que «siente instintivamente la agonía de su raza» (Beck-Bernard, 1991: 52).

Tanto Beck-Bernard como Sarmiento representan literariamente el realismo romántico del siglo XIX. Sus escritos manifiestan el claro compromiso históricosocial que los caracterizó (y en el caso de Sarmiento, hablamos también de lo político) pero están imbuidos a la vez de una belleza de la prosa que exalta el espíritu romántico en las historias narradas y en las descripciones del ambiente y del paisaje.

La descripción de Lina Beck en el capítulo «El río Paraná» es un texto exultante de lirismo caracterizado por la enumeración de abundantes especies vegetales, algunas exóticas, y el tratamiento hiperbólico de un paisaje idílico que se torna casi irreal. La enumeración de los alimentos de la cena seguida de la presentación minuciosa de la exuberancia de la naturaleza, de un cierto barroquismo, trae a la memoria los textos de viajeros y exploradores naturalistas que recorrieron los ríos y las vastas extensiones de la América del Sur (von Humboldt, Amado Bompland, Darwin). En De los espejos y otros ensayos, Umberto Eco sentencia que «no se puede dejar de mirar las cosas con los ojos de la cultura» (Eco, 1992: 70). De este modo, el punto de vista de nuestra autora es el del europeo que no puede evitar la comparación con invernaderos y jardines de la vieja Europa y da a su escritura el tono de lo ajeno y de lo extraño que se manifiesta, en este caso, en el sentimiento de admiración como no sucede en otras descripciones donde lo que se evidencia es la mirada escrutadora del juicio. Es una escena que se mueve y sumerge a los viajeros en un abigarramiento de colores, formas, luces y vapores.

Cenamos temprano. Suracco, de sueño tan pesado como el de Epiménides, no sale de su envoltura. Manuelo es sustituto, nos sirve un excelente yantar y nos da como postre nueces de la cordillera y uvas de Mendoza, todo acompańado de vino Carlón y café. Terminada la 
cena, el buen capitán advierte nuestros deseos de dar un paseo en bote y hace preparar una canoa. No tardamos en bordear la isla que, de cerca, diríase el invernadero de algún jardín real, en Europa. Un arroyo atraviesa la isla. Entramos en él bajo una glorieta de lianas florecidas, que se entrecruzan de una margen a otra, formando arcos magníficos y festones que rozan nuestras cabezas. Los árboles más variados sombrean las orillas. Podemos admirar los ceibos soberbios, cubiertos de racimos de un rojo de púrpura, las azaleas de todos colores: blanco, rosa, anaranjado, amaranto; magnolias enormes; naranjos silvestres cargados de flores y frutas; durazneros también silvestres de frutas exquisitas, mangos, tamarindos, mimosas, áloes gigantescos, cactos imponentes llamados órganos y otros no menos grandes que producen el higo moro; floripondios, trepadoras cubiertas de graciosas florecillas bermejas, níveas, violetas; pasionarias cuyo fruto dorado pende con elegancia entre los delicados tallos. Los bambúes esbeltos comienzan a balancearse dulcemente bajo la brisa de la noche, cargada de mil aromas fuertes y penetrantes. La barca resbala sin ruido sobre el agua transparente. La superficie desaparece a trechos bajo vergeles flotantes formados de ninfeas de un color lila encarnado y de nenúfares enormes cuya flor semeja una copa de alabastro colocada sobre las anchas hojas. Pasamos junto a la magnífica planta que llaman los criollos maiz de la isla, de flor que finge una lámpara antigua suspendida por algún hilo muy leve. Un lindo pájaro blanco surge de pronto entre esas soledades floridas, cruza el arroyo y busca asilo en la margen opuesta. Anochece. Emprendemos el regreso. Al salir de la galería de ramajes y flores que hemos recorrido, entramos de nuevo en el Guazú. El sol se pone entre un mar de fuego, al que sucede luego un ambiente vaporoso, como espolvoreado de oro, que envuelve por un instante las islas, el cielo y el río. Este fulgor mágico se apaga con sorprendente rapidez para hacer lugar a una espléndida noche. (Beck-Bernard, 1991: 35)

El pintoresquismo que caracteriza las descripciones de la «Fiesta de la Virgen de Guadalupe» ilumina las escenas a la manera de finas estampas y cuadros de un colorido singular. Personajes de distintas clases sociales, escenas irreales y una para nada velada referencia irónica y humorística a las supersticiones que suelen engendrar las creencias religiosas, hacen de este capítulo una preciosa página literaria. La autora cierra este texto con una bellísima descripción del crepúsculo, de sello claramente intimista y romántico, en el que los colores y los objetos van degradando paulatinamente hacia la oscuridad y la soledad total:

El sol se hunde en el horizonte, entre un mar de nubes purpúreas que acompañan siempre a los crepúsculos en este país. Los gallardos jinetes, las graciosas amazonas, las carretas, los coches, todos emprenden camino a la ciudad. La atmósfera se llena de resplandores rosas y reflejos dorados que dan a los objetos aspectos extraños. Llega la noche. Únicamente la pequeña cruz dorada que remata la cupulita de la iglesia, brilla todavía un momento en el horizonte como una estrella fija. Pero este fulgor también se apaga. Pronto la soledad y el silencio, huéspedes habituales del lugar, reinan con las sombras de la noche sobre la capilla de Nuestra Seńora de Guadalupe. (Beck-Bernard, 1991: 56)

Con igual detallismo describe un incendio de campos en el capítulo «Las quemazones». Pero el tratamiento literario del paisaje es aquí consecuentemente grave y trágico. La prosopopeya contribuye a la animación vigorosa de la escena y a su grandiosidad, borrando las fronteras entre descripción y relato. Es el viento que «lleva y trae las olas de fuego», son los pastos que recubren y descubren el terreno, las llamas que «retroceden», «voltejean» y saltan de un matorral a otro. 
En esto echamos de ver en el horizonte una faja de humo negro que parece adelantar hacia nosotros con notable rapidez. De vez en cuando, entre esa barra compacta que avanza, se abren algunos boquetes que arrojan llamas rojas y amarillas. Es una quemazón o incendio de campos. El espectáculo se hace cada vez más grandioso. La llanura queda pronto convertida en un mar candente donde el viento lleva y trae las olas de fuego. Por instantes, desplazándose con movimientos de marea, las llamas retroceden dejando ver el suelo ennegrecido, veteado a trechos de gris y blanco por la naturaleza del terreno. En seguida los pastos abrasados vuelven a recubrir el suelo al soplo del viento y las llamas voltejean caprichosamente, saltando de un matorral a otro. (Beck-Bernard, 1991: 61)

En su Facundo, Sarmiento describe distintas zonas del país desde el punto de vista del nativo, imbuido él mismo de las características de esa geografía y en estrecha relación con los propósitos ideológicos que animan su escritura.

La inmensa extensión del país que está en sus extremos es enteramente despoblada, y ríos navegables posee que no ha surcado aún el frágil barquichuelo. El mal que aqueja a la República Argentina es la extensión: el desierto la rodea por todas partes, se le insinúa en las entrańas; la soledad, el despoblado sin una habitación humana, son por lo general los límites incuestionables entre unas y otras provincias. Allí, la inmensidad por todas partes: inmensa la llanura, inmensos los bosques, inmensos los ríos, el horizonte siempre incierto, siempre confundiéndose con la tierra entre celajes y vapores tenues que no dejan en la lejana perspectiva seńalar el punto en que el mundo acaba y principia el cielo. (Sarmiento, 1971: 24)

Podemos percibir en este fragmento las coincidencias de apreciaciones de Sarmiento y Lina Beck-Bernard, si bien desde distintos lugares de observación: la inmensidad del territorio, el desierto siempre presente y la soledad de las vastas extensiones. La mirada de Lina es la de la perplejidad del viajero que observa y describe con asombro; la de Sarmiento, en cambio, es la del gaucho que sufre el desamparo de su propia tierra.

Sarmiento describe el territorio como un geógrafo. De hecho en Recuerdos de Provincia manifiesta su temprana inclinación al estudio de la geografía. Así, se refiere a la parte habitada del país dividiéndola en tres zonas distintas que presentan fisonomías características y que condicionan el modo de ser de sus habitantes, concepto que vemos también en Lina Beck-Bernard. Lo curioso en estas descripciones de la Pampa que hace Sarmiento es que, al momento de escribir estas líneas, no la conocía; y de este modo se inscribe en la tradición literaria medieval de las invenciones topográficas en los relatos enciclopédicos de «las maravillas del mundo que debían existir» (Eco, 1992: 68). El estilo poético de su escritura no retacea paralelismos y metáforas, como "la imagen del mar en la tierra», los «matorrales enfermizos», la «lisa y velluda frente» de la pampa, y el desierto que espera el trabajo del hombre para transformarse: «la tierra aguardando todavía que se le mande producir las plantas y toda clase de simiente»:

La parte habitada de este país privilegiado en dones y que encierra todos los climas puede dividirse en tres fisonomías distintas, que imprimen a la población condiciones diversas, según la manera como tiene que entenderse con la naturaleza que la rodea. Al norte, confundiéndose con el Chaco, un espeso bosque cubre con su impenetrable ramaje extensiones que llamáramos inauditas, si en formas colosales hubiese nada inaudito en toda la extensión de la América. 
$\mathrm{Al}$ centro, y en una zona paralela, se disputan largo tiempo el terreno la pampa y la selva; domina en partes el bosque, se degrada en matorrales enfermizos y espinosos, preséntase de nuevo la selva a merced de algún río que la favorece, hasta que al fin, al sur, triunfa la pampa y ostenta su lisa y velluda frente, infinita, sin límite conocido, sin accidente notable: es la imagen del mar en la tierra; la tierra como en el mapa; la tierra aguardando todavía que se le mande producir las plantas y toda clase de simiente. (Sarmiento, 1971: 24)

Más adelante describe una escena que había presenciado en la Sierra de San Luis, en 1838, en el medio del campo. Es ésta una descripción idílica de rebaños y personas que se reúnen a la oración y que lo remonta a la antigüedad. Además de la alusión al origen europeo del dueño de casa, describe el momento mismo de la plegaria y alude al sentimiento de religiosidad que pudo experimentar. El texto es sencillo, adecuado e intimista. Aquí hay una valoración positiva de un sincero (pero no frecuente) sentimiento religioso que se distancia de «un sermón pagado de cien pesos» del que habla Lina Bernard en la «Fiesta de Guadalupe».

Era aquél un cuadro homérico: el sol llegaba al ocaso; las majadas que volvían al redil hendían el aire con sus confusos balidos; el dueño de casa, hombre de sesenta años, de una fisonomía noble, en que la raza europea pura se ostentaba por la blancura del cutis, los ojos azulados, la frente espaciosa y despejada, hacía coro, al que contestaban una docena de mujeres y algunos mocetones, cuyos caballos, no bien domados aún, estaban amarrados cerca de la puerta de la capilla. Concluido el rosario, hizo un fervoroso ofrecimiento. Jamás he oído voz más llena de unción, fervor más puro, fe más firme, ni oración más bella, más adecuada a las circunstancias que la que recitó. Pedía en ella a Dios lluvia para los campos, fecundidad para los ganados, paz para la república, seguridad para los caminantes... Yo soy muy propenso a llorar, y aquella vez lloré hasta sollozar, porque el sentimiento religioso se había despertado en mi alma con exaltación y como una sensación desconocida, porque nunca he visto escena más religiosa; creía estar en los tiempos de Abraham, en su presencia, en la de Dios y de la naturaleza que lo revela; la voz de aquel hombre candoroso e inocente, me hacía vibrar todas las fibras y me penetraba hasta la médula de los huesos. (Sarmiento, 1971: 34)

Tanto en el libro de Sarmiento como en la obra de Lina Beck-Bernard que estamos analizando, la descripción es generalmente «ancilla narrationis, esclava siempre necesaria pero siempre sometida..." y suspende el curso del tiempo instalando el relato en el espacio (Genette, 1974: 199-201).

En el siguiente fragmento de Cinco años..., la descripción corresponde a un cuadro (tal como lo define la autora) interior de un patio vecino visto desde la azotea de su casa. Aquí los personajes están en sus actividades cotidianas y representan distintos tipos humanos y clases sociales: mozas pardas y mulatas que realizan las tareas domésticas, niños que parecen estar suspendidos en una edad de oro debajo de los naranjos, una criolla elegante que se ocupa de su cabello, viejas fumadoras de cigarros, una indiecita que prepara el mate, jovencitas que bordan y hacen encajes. Priman los detalles y la enumeración de los elementos, aunque la descripción no carece de juicios de valor: «se arrebozan graciosamente», «muy elegante», «con gracia muy española», «son de inteligencia poco cultivada». Toda la escena bulle de colores y acciones y, aunque resulta abstraída del tiempo del relato, constituye una descripción significativa en la diégesis por el análisis socioantropológico de los personajes que componen el ambiente santafesino en el que ocurren los hechos narrados. 
Las escenas en los patios de las casas vecinas forman la parte más original de nuestro cuadro. De un aljibe, que ocupa el centro de un patio, sacan agua y llenan sus tinajas algunas mozas pardas y mulatas. Llevan en la cabeza un chal de colores muy vivos con el que se arrebozan graciosamente. Otras pisan maíz en grandes morteros hechos en troncos de algarrobos. Este maíz lo dedican a la mazamorra, plato favorito de la región que cocinan en una olla puesta sobre dos ladrillos. La olla, con una o dos cacerolas de cobre, un cuchillo y algunas conchas de nácar, que hacen de cucharones, componen todo el ajuar culinario. La cocina misma está constituida a menudo por un cobertizo de cańas o palmas sostenido por macizos pilares. Una cocina cerrada con puertas y ventanas es lujo inusitado y no ofrece mucho atractivo con sus paredes ahumadas y cubiertas de hollín. En el patio más próximo varios niños juegan bajo los naranjos y hacen caer las frutas doradas que cuelgan de las ramas en profusión. Algo más lejos, una criolla muy elegante ha colgado un espejito de un pilar y alisa y adereza sus abundantes cabellos con gracia muy española. Algunas mujeres viejas, sentadas bajo un corredor, lían hojas de tabaco sobre sus rodillas, hacen con ellas enormes cigarros y se ponen a fumar. A pocos pasos, una indiecita, sentada en cuclillas pone a hervir agua en una pava y tiene en su mano preparado un mate de plata. Espera que hierva el agua para cebarlo y servirlo a las fumadoras. Bajo el mismo corredor, algunas jovencitas bordan y hacen encajes. Es en realidad su principal ocupación porque son de inteligencia muy poco cultivada. (Beck-Bernard, 1991: 38)

La función significativa de la descripción en el libro de Sarmiento está claramente representada en el tratamiento del rastreador, el baqueano, el gaucho malo y el cantor, personajes de la pampa cuya originalidad y caracteres el autor pinta como argentinos. En este sentido, reafirma la incidencia directa del paisaje en las "costumbres y usos peculiares» en un sentido universal y su supervivencia en los caudillos, que ilustran la barbarie en su expresión más acabada. Pero la descripción de tipo humano inspirada en la frenología y la fisionomía natural que se imponían en el siglo XIX, alcanza su mejor ejemplo en la estampa de la figura de Facundo:

Facundo, pues, era de estatura baja y fornida; sus anchas espaldas sostenían sobre cuello corto una cabeza bien formada, cubierta de pelo espesísimo, negro y ensortijado. Su cara, un poco ovalada, estaba hundida en medio de un bosque de pelo, a que correspondía una barba igualmente espesa, igualmente crespa y negra, que subía hasta los juanetes bastante pronunciados para descubrir una voluntad firme y tenaz. Sus ojos negros, llenos de fuego y sombreados por pobladas cejas, causaban una sensación involuntaria de terror en aquellos sobre quienes alguna vez llegaban a fijarse, porque Facundo no miraba nunca de frente, y por hábito, por arte, por deseo de hacerse siempre temible, tenía de ordinario la cabeza inclinada, y miraba por entre las cejas, como el Alí-Bajá de Montvoisin. (Sarmiento, 1971: 73)

Sarmiento ensaya aquí la descripción del prototipo del caudillo, temible y admirado a la vez, cuyos rasgos físicos subrayan la brutalidad y la oscuridad del personaje, la barbarie. Al igual que en la escena de Lina Beck-Bernard, aquí también la descripción del tipo social si bien suspende el tiempo del relato, lo alimenta simbólicamente. 


\section{Hacia el punto de tangencia: Santa Fe de la Vera Cruz, 1860}

Tanto Sarmiento como Lina Beck-Bernard constituyen dos claros testimonios de su tiempo y de la sociedad en la que vivieron. Ambos fueron atravesados por la atmósfera social y política que respiraron. Y en un momento dado de sus vidas coincidieron en el espacio y en el tiempo. El punto de tangencia fue Santa Fe de la Vera Cruz en 1860. "Santa Fe, situada en la confluencia del Paraná y otro río navegable que desemboca en sus inmediaciones, es uno de los puntos más favorecidos de América y sin embargo no cuenta hoy con dos mil almas...» (Sarmiento, 1915: 64).

Ese año se crea el Municipio, tal como lo expresa Ana María Cecchini de Dallo:

Para detectar algunas normas regulatorias de la vida en la ciudad hay que comenzar en 1860 con la creación del Municipio. Hasta esa fecha perduraron como uso y costumbre las que impusiera el Cabildo desaparecido en 1830, ya que durante los 30 ańos restantes la ciudad careció de un gobierno propio y compartió el gobierno provincial del cual era sede. (Cecchini, 2005: 7)

La mayor densidad edilicia se daba en las calles Comercio (hoy San Martín) y San Jerónimo, donde se ubicaban las casas de mayor calidad, de azotea y de teja. Según afirma Cecchini, la casa que ocupan Charles y su esposa no «eran consideradas de alto a pesar de tener el altillo y el balcón mirador a la calle». En ese mismo año, don Hermenegildo Zuviría (Merengo), ya conocedor del arte de confeccionar alfajores como los hacían las «viejas Piedrabuena», se instala por su propia cuenta en la misma esquina de San Jerónimo y 3 de Febrero, sede de tantas tertulias, altercados políticos y tránsito de los gringos hacia las colonias en el camino del incipiente progreso urbano. En el casco urbano de la ciudad sobresalía el Cabildo, frente a la Plaza Mayor.

En las salas de la galería alta se reunieron los convencionales Constituyentes, a través de cuyas puertas llegaba el aire del río y el sonido de las campanas. La plaza parecía en los años 1853 a 1860 un campito rodeado de postes y sombreado por paraísos... Se entraba al Cabildo por un ancho zaguán que llevaba al patio principal y a la izquierda comenzaba la escalera de peldaños de ñandubay y barandas de hierro que comunicaba con el piso alto. En sus salones se realizaban las sesiones de las Convenciones y de la Cámara de Representantes y también tertulias o bailes... (Pérez Martín, 1965: 46-47).

Durante el gobierno de Juan Pablo López, en abril de 1857, llega Lina BeckBernard en una goleta al puerto de Santa Fe «el mejor y más seguro de la Confederación argentina», dice la autora citando al Comandante Page. Y continúa: «En la ciudad, las casas de aspecto morisco y las torres de las iglesias brillando entre los follajes oscuros de los naranjales, dominados por esbeltas palmeras que se balancean al viento" (Beck-Bernard, 1991: 37).

La vereda oeste, frente a la Plaza, «donde hoy están los tribunales, tenía casonas, negocios, fonda u hotel, el Club del Orden... La fonda tenía un balcón en el segundo piso, desde el cual Lina Bernard observó la vida de la ciudad», dice José Pérez Martín (1965: 46).

En 1858 asume la Gobernación Rosendo María Fraga, en un clima de desencuentros que traía rumores de guerra entre la Confederación y la Provincia de Buenos Aires. Después de la batalla de Cepeda, el 23 de octubre de 1859, con 
el triunfo de Urquiza, y en cumplimiento del Pacto de San José de Flores, que prevé la incorporación de Buenos Aires a la Confederación, se hace necesaria la modificación de la Constitución Nacional de 1853, para introducir las reformas propuestas por la Provincia de Buenos Aires.

El 14 de setiembre de 1860, durante la Presidencia de Santiago Derqui y la Gobernación de Santa Fe en manos de Pascual Rosas, se realiza la primera Sesión Preparatoria de la Convención Nacional «Ad Hoc» nombrada para examinar las reformas propuestas por Buenos Aires a la Constitución Nacional de 1853. Bajo la Presidencia de Mariano Fragueiro, se reúnen en el Cabildo de Santa Fe los Convencionales en representación de catorce provincias. Entre ellos Valentín Alsina, Nicasio Orońo, Marcos Paz, Juan Pujol, Juan Francisco Seguí, José Mármol, Rufino de Elizalde, Dalmacio Vélez Sarsfield, Salvador María Del Carril, Pascual de Echagüe, Lucio V. Mansilla y Domingo Faustino Sarmiento, en representación de Buenos Aires. Las sesiones fueron diarias y públicas o secretas según determinara la Convención. En la segunda sesión preparatoria, es original la intervención de Sarmiento en referencia al nombre "Constitución de Mayo» que un Ministro del Ejecutivo Nacional daba a la Constitución del año 53 en una nota dirigida a la Convención, alegando que era impropio y «que éste podría ser un nombre cariñoso dado a un acontecimiento o a una fecha; pero que en manera alguna podía designarse así el Código de la Nación Argentina». En esa misma reunión, Sarmiento solicita que se impriman copias del Reglamento para que los Diputados «pudiesen estudiarlo». El 21 de setiembre, el Presidente Mariano Fragueiro declara instalada la Convención Nacional «Ad Hoc». Las reformas propuestas por Buenos Aires fueron tratadas en particular. A las cuestiones de los impuestos aduaneros, los derechos de importación y el nombre de la República Argentina se agregaron otras referidas a las limitaciones de la intervención federal en las provincias, la abolición de la esclavitud y la supresión de ejecuciones a lanza y cuchillo. Se estableció la adopción del jus soli en lugar del jus sanguinis para la ciudadanía, resolviendo preventivamente de este modo un problema evidente en un país que era ya de inmigración. En la tercera sesión ordinaria, del 23 de setiembre, se trata el destino de los muebles utilizados durante la Convención. Sarmiento opina que algunos de esos objetos deberían entregarse a la Cámara de Diputados del Congreso Argentino y «el resto al Cabildo de Santa Fe, como un recuerdo de la Convención». Finalmente, el Sr. Mármol expresa que: «en ese recinto (el Salón principal del Cabildo de Santa Fe) se había realizado la unión y debía quedar en él todo lo que lo decoraba, para que cada sillón recordase aquel hecho y a los que los habían ocupado» (Actas de la Sesiones, 1860: 32).

La decisión al respecto, y de acuerdo con el criterio de Mármol, se comunica en los Oficios Número 6 y 7 del 25 de setiembre de 1860. Sarmiento agrega que se disponga la publicación de todos los actos de la Convención en el mismo formato que el de la Convención examinadora de Buenos Aires.

Las sesiones comenzaban por la tarde y finalizaban alrededor de las diez de la noche, de modo tal que los asistentes a la Convención, que duró poco más de diez días, disponían de una cierta cantidad de horas libres para conocer la ciudad, hacer vida social y asistir a algún agasajo especial. Para ello, además del Cabildo, se contaba con el Club del Orden, fundado el 27 de febrero de 1853, en la casa de Don José María Cullen, en ocasión de la Convención que redactó la Constitución Nacional. En el Acta de fundación se establece que el Club carece de tendencia 
política alguna y su finalidad es meramente social «siendo una de sus miras especiales recomendar la sociedad santafesina a los ojos del extranjero por medio de una hospitalidad despreocupada y generosa» (López Rosas, 1993: 176 a 178). Sus socios reunían lo más conspicuo de la sociedad santafesina de aquellos ańos ligada a los poderes políticos y a las empresas colonizadoras y funcionó por primera vez en la calle 23 de Diciembre, hoy General López. La misma Lina Beck- Bernard alude en dos oportunidades al Club del Orden en su obra: una que refiere a un baile de Carnaval y otra, a la fiesta organizada por la colectividad italiana para festejar la entrada de Garibaldi en Nápoles, en octubre del año 60.

El martes por la noche hay baile de fantasía en el Club del Orden, al que concurrimos. Las damas visten de calle; sólo algunos jóvenes llevan trajes característicos pero sin lujo alguno. Yo lo hago notar a mi vecina, dońa Trinidad. (Beck-Bernard, 1991: 57)

La comisión directiva del Club del Orden ofreció los salones del local a un Comité de Fiesta italiano, que organizó para esa misma noche un lindo baile. La sala estaba adornada con guirnaldas de flores y colgaduras de telas rojas, verdes y blancas. (Ibid.: 67)

El 27 de agosto de 1860, en vísperas de la Convención Reformadora, es elegido Presidente del Club del Orden Charles Beck, quien duró en sus funciones hasta el 27 de febrero de 1861. En las Actas del Club se lee que en la reunión del 13 de setiembre, la Comisión discute acerca de la iluminación de la sede con dos lámparas «como de ordinario, esto es con las dos lámparas que se acostumbraban encender y si se debía poner la alfombra nueva puesto que era un caso excepcional y por un tiempo determinado» dado que ese era el único punto de reunión en las horas que los Diputados estuviesen desocupados. Además, se decide por votación nombrarlos Socios Honorarios. El 21 de setiembre, la Comisión acuerda dar un baile en honor de los señores Convencionales, con un costo de ciento cincuenta pesos, ya que «no era propio que el Club se sujetase tan sólo a la tertulia que ordena el Reglamento». En los Anales del Club puede leerse que

se alumbra el club y se coloca la alfombra nueva, para recibir a los diputados de la Convención Constituyente que se realizaba en la ciudad. Se designan socios honorarios a los Diputados. Se realiza un baile en honor de los convencionales, el que fue financiado con los dineros del club y el aporte voluntario de los socios. (De Diego, 1990: 17-18)

Siendo su esposo el Presidente del Club del Orden y teniendo en cuenta el temperamento vivaz, curioso y sociable de Lina Bernard es posible pensar que haya asistido a distintas tertulias y al baile organizado para agasajar a los Convencionales. Y por otro lado, considerando la actitud galante y gentil hacia las damas que distinguió siempre a Sarmiento, de 49 años a la sazón, admirador de la belleza y de la inteligencia de la mujer, no sería improbable que se haya acercado a la bella e inteligente Lina, de escasos 36 ańos, como puede observársela en un autorretrato. Es aquí donde quizás estas vidas que transcurrían en paralelo hayan encontrado ese punto de la tangente al que nos referíamos en el título de este trabajo. Y aquí es también donde la pudorosa historia nos abandona y da paso a la conjetura de hechos que no pueden ya corroborarse, pero que podrían haber sucedido. Los datos históricos constituyen los indicios en la trama de las coincidencias. Las concordan- 
cias ideológicas y literarias sustentan la confluencia intelectual. Bastaría solamente un testimonio del encuentro, que no hemos podido hallar fehacientemente.

En Nuevas Inquisiciones, Borges cita a Schopenhauer: «El tiempo es como un círculo que girara infinitamente: el arco que desciende es el pasado, el que asciende es el porvenir; arriba, hay un punto indivisible que toca la tangente y es el ahora» (Borges, 1960: 239).

Parafraseando a Schopenhauer podríamos sospechar que esas dos líneas son los cursos de las vidas de Lina Beck-Bernard y Domingo Faustino Sarmiento, tocándose en un punto indivisible del tiempo y del espacio. Rectas, figuras, espacios tangentes, y quizás una nueva dimensión: la de los tiempos tangentes en la vida de los hombres. Siempre que no tratemos de refutarlos. ${ }^{1}$

\author{
Notas \\ ${ }^{1}$ Agradecimientos: Sra. María Teresa Biagioni, Prof. Mercedes N. Romero \\ de Díaz, Dr. Julio Del Barco y Dr. Julio Gómez por su contribución \\ bibliográfica para este trabajo. Y al Cav. Mgter. Adriana C. Crolla por \\ haber iniciado la puesta en valor y los estudios sobre Lina y Charles, \\ figuras casi olvidadas de la historia.
}

\title{
Referencias bibliográficas
}

Actas de las Sesiones de la Convención Nacional ad hoc. (1860). Publicación Oficial [en línea]. Buenos Aires: Imprenta del Comercio del Plata. Consultado 20-05-18 en http://www.adaciudad.org.ar Alberdi, J.B. y Sarmiento, D.F. (2005). La gran polémica nacional. Cartas Quillotanas. Las ciento y una. Buenos Aires: Editorial Leviatán. Bachtin, M. (2001). Estetica e romanzo. Torino: Einaudi.

Beck-Bernard, L. (1991). Cinco años en la Confederación Argentina 1857-1862. [Trad. José Luis Busaniche]. Santa Fe: Imprenta Legislativa de la Provincia de Santa Fe.

(2018). Trilogía narrativa y ensayos. (Crolla, A. ed.) [Trad. Silvia Zenarruza-Veronica Cerati]. Santa Fe: Ediciones UNL.

Beck-Bernard, C. (2015). La República Argentina. (Crolla, A. ed.). [Trad. Lutecia Piarrou. Rev. Silvia Zenarruza-Verónica Cerati]. Santa Fe: Ediciones UNL.

Borges, J.L. (1960). Otras inquisiciones. Buenos Aires: Emecé.

Botana, N. (2001). Domingo Faustino Sarmiento: El orden republicano, 1852-1874. Biblioteca Virtual Miguel de Cervantes [en línea]. Consultado 19-10-18 en www.cervantesvirtual.com

Cecchini de Dallo, A.M. (2005). La evolución edilicia de la ciudad de Santa Fe 1860-1875/76. Esperanza: Asociación Amigos del Archivo General de la Provincia.

Crolla, A. «Voces silentes y contrapuntos heterotópicos sobre el fenómeno inmigratorio Recuperaciones de los Beck Bernard y de Laura Pariani 
desde la academia argentina». Rev. Civitas, Porto Alegre, v. 15, n. 3, p. 453-472, jul.-set. 2015. Cons. en http://revistaseletronicas.pucrs.br/ ojs/index.php/civitas/article/view/19665

(2018). «Lina Beck-Bernard, migración y género». II Jornadas de Migraciones. Problemas, alcances y Debates en perspectivas Interdisciplinarias. Buenos Aires: Universidad de José C. Paz. ISSN 2591-3751, pp. 305-314

Damianovich, A. (1988). Breve Historia de Santa Fe. Santa Fe: Distribuidora Litar S.A.

De Diego, B. (1990). Anales del Club del Orden. Contribución a la Historia de Santa Fe. Santa Fe: Imprenta Macagno S.R.L.

Di Filippo, L. (1949). Cinco semblanzas. Paraná: Nueva Impresora (Bresto \& Viñas París).

Eco, U. (1992). De los espejos y otros ensayos. Buenos Aires: Lumen.

GenetTe, G. (1974). Fronteras del relato en Análisis Estructural del relato. Comunicaciones no 8. Buenos Aires: Editorial Tiempo Contemporáneo. Gianello, L. (1966). Historia de Santa Fe. Santa Fe: Castellví S.A.

Jitrik, N. (1968). Muerte y Resurrección de Facundo. Buenos Aires: Centro Editor de América Latina.

Lamothe, E.A. (1987). La pequeña historia. Santa Fe: Canal 13 Santa Fe de la Vera Cruz. Editorial Colmegna.

López Rosas, J.R. (1993). Santa Fe. La perenne memoria. Santa Fe: Municipalidad de la ciudad de Santa Fe.

LuKacs, G. ET AL. (1972). Polémica sobre realismo. Buenos Aires: Editorial Tiempo Contemporáneo.

Martínez Estrada, E. (1969). Sarmiento. Buenos Aires: Editorial Sudamericana.

Otтolenghi, J. (1950). Vida y obra de Sarmiento en síntesis cronológica. Buenos Aires: Editorial Kapelusz.

Pérez Martín, J. (1965). Itinerario de Santa Fe. Santa Fe: Colmegna. Rodil, M. (1994). Puerto perdido. Santa Fe: Ediciones UNL.

Rojas, R. (1945). El profeta de la pampa. Vida de Sarmiento. Buenos Aires: Losada.

Sarmiento, D.F. (1971). Facundo. Buenos Aires: Losada.

(1915). Conflicto y armonías de las razas en América. Buenos Aires: La Cultura Argentina.

(2003). Recuerdos de Provincia [en línea]. Consultado 14-10-18 en https://www.biblioteca.org.ar/libros/71205.pdf Valenzuela, D. y Sanguinetti, M. (2012). Sarmiento periodista. El caudillo de la pluma. Buenos Aires: Edit. Sudamericana.

VItTORI, J.L. (1999). Viajes y viajeros en la literatura del Río de la Plata. Tomo II. Buenos Aires: Ed. Vinciguerra. 